\title{
PERCEPTION OF CORONAVIRUS AS AN EXISTENTIAL THREAT AND CONFORMANCE WITH SOCIAL DISTANCE PROTOCOL
}

\author{
${ }^{* 1}$ Labe, R. M., ${ }^{2}$ Otene, A. S., ${ }^{3}$ Inunduh, P. M., \& ${ }^{4}$ Akume, G. T. \\ ${ }^{* 1}$ Department of Clinical Psychology, Federal Medical Centre Makurdi, Benue State, Nigeria \\ *Corresponding Author Email: laberansome@ gmail.com \\ ${ }^{2}$ Consultant Oncologist, Federal Medical Centre Makurdi, Benue State, Nigeria \\ sammy4ng@yahoo.com \\ ${ }^{3}$ Consultant General Surgeons, Federal Medical Centre Makurdi, Nigeria \\ ${ }^{4}$ Professor of Counselling Psychology, Department of Educational Foundation, Benue State University, Nigeria \\ gabakume@gmail.com
}

\begin{abstract}
The study assesses perception of coronavirus as an existential and conformance to social distance among citizens in Benue state. A total of 343 participants comprised of 187(54.5\%) males and 157(45.8\%) females. Participants responded to a self-developed questionnaire which has a Cronbach alpha coefficient was.76. The study was a correlational research design. Results, shows there is a significant positive correlation between conformists' perception of coronavirus as an existential threat and conformance to social distance, $r(343)=.559, \mathrm{p}<$ .0 .01 for hypothesis one. There was a negative correlation between oppositional group perceptions of coronavirus as an existential threat and conformance to social distance, $r(343)=-.175, p<.0 .01$ for hypothesis two. Hypothesis three shows there is a significant difference in the perception of coronavirus as an existential threat and conformance to social distance between conformists score ( $M=12.7360$, $S D=2.39721)$ and oppositional score $(M=16.0242,=3.03586), t(341)=-7.012, p<.05)$. A significant difference was also observed in the perception of coronavirus as an existential threat and conformance to social distance between the male scores of $(M=14.3520, S D=4.47642)$ and female scores of $(M=14.5137, S D=4.84979), t(323)=-3.312, p<.05)$. Findings from this study show that, coronavirus is an existential threat to human life. Nevertheless, people differed in their attitude to conformance to social distance protocol. The peoples' view of coronavirus and response to social distance should help to deepen government and health managers understanding to strengthen health policy and measures on disease control in future outbreaks.
\end{abstract}

Keywords: Coronavirus, Existential threat, Social distance, Conformist group, Oppositional group

LICENSE: This work by Open Journals Nigeria is licensed and published under the Creative Commons Attribution License 4.0 International License, which permits unrestricted use, distribution, and reproduction in any medium, provided this article is duly cited.

COPYRIGHT: The Author(s) completely retain the copyright of this published article.

OPEN ACCESS: The Author(s) approves that this article remains permanently online in the open access (OA) mode.

QA: This Article is published in line with "COPE (Committee on Publication Ethics) and PIE (Publication Integrity \& Ethics)". 


\section{INTRODUCTION}

Coronavirus disease (Covid-19) is caused by SARs-COV-2 a newly emergent coronavirus that was detected in some people in Wuhan province in China at the end of December, 2019 (World Health Organization). Covid-19 which was declared a pandemic by the WHO on the $11^{\text {th }}$ March, 202 inevitably has instantaneously disproportionate negative impact on the physical and mental health on the international community. The head of the African Centre for Disease Control and prevention (African CDC) warned that coronavirus posed "an existential threat to our continent" (Sanderson, 2020). Consequently, as states struggle to get the Covid-19 balance right-between eased restrictions and rising infection rates (Honeycut, 2020); it falls on people to abide by the recommended prevention guidelines such as wearing of face mask, hand washing with soap and use of hand sanitizers. Strengthening these safety health measures was the social distance and a lockdown order which swiftly led to the decongestion of the public space. The social distance order remains an important measure for the effective control of the spread of this contagious virus disease which has no immediate curative medication or vaccine to protect people against getting infected. Social distance refers to measures aimed at reducing interaction within a community, which can include infected individuals as yet unidentified, hence not in isolation (Aquino et al., 2020). Since disease transmitted through respiratory droplets from sneezing and coughing requires a certain physical proximity for contagion to occur, social distance invariably reduced transmission (Aquino et al., 2020). Social distancing also known as physical distancing entails people maintaining a safe space between themselves and others who are not from your family or home. Social distance requires everyone to stay six feet (about 1.5 to 2feet) away from other people if it becomes necessary for anybody to go out in the public space (CDC, 2020; NCDC, 2020; WHO, 2020).

Compliance to social distance and other guidelines is to continue until people develop enough immunity against the virus and better still a safe and effective vaccine is found and delivered to the population. Apparently, when the coronavirus started invading the boundaries of countries in the world at a pandemic magnitude, the first case of coronavirus was detected in in an Italian engineer with the Larfarge Ewekoro Cement Company in Ogun State, Nigeria on return from Milan (Federal Ministry of Health, 2020). At the instant of this first reported case, Nigerian government acted quickly as there were already fears that the virus could travel through the regions of the country. The Federal Ministry of Health working in collaboration with the Nigerian Centre for Disease Control (NCDC) fast forwarded the safety health prevention guidelines rolled out by the WHO to citizens to practice for early arrest of escalation of cases and forecasted community transmission episode. Feared escalation of cases prompted the federal government to announce a total lockdown of Lagos, Ogun and Abuja. This was followed by state governors' introduction of dusk to down curfews to limit peoples' movement and social distancing was emphasized for the people to observe in outdoor activities. Social distance required people to maintain $1 \frac{1}{2}$ to 2 metres distance between oneself and anyone who is coughing and sneezing, mask wearing, hand washing, and use of 60-70\% alcohol-based hand sanitizers (NCDC, 2020; WHO, 2020). Consequently, public social gathering was limited to not more than 20 persons and to ensure compliance, markets were closed, and social and traditional occasions like burial ceremonies were banned, cinema halls and football viewing centres, restaurants, bars, churches and sports arenas were all closed (Benue State Task Force on Covid-19, 2020). 


\section{LITERATURE REVIEW}

The social media platform was flood with misinformation, frightening statistics, practical advice or gallows humour (Robson, 2020). Practically and for months, the tsunami of information released to the global population about the novel virus from the electronic and print media created great fear and anxiety. The constant bombardment with coronavirus has the potential to induce traumatic emotional experience in some people who were infected or not infected but of course affected. Besides, the unremitting feeling of threat may have other more undetected effects on individual's physical and mental health. Actually, to people who are experiencing a disease phenomenon, naturally because of some deeply evolved responses to disease, fears of contagion lead us to become more conformists...and less accepting of eccentricity (Robson, 2020). As a result, anything that is seen to reduce the risk of infection in the first place is quickly adopted for a distinct advantage. Doing so, people instinctively developed a set of unconscious psychological responses which has been termed behavioural immune system to act as a first line of defense to reduce contact with potential pathogens (Robson, 2020). According to behavioural immune system (John, Natalie, \& Michael, 2013) people are likely to develop negative emotions (Mortensen, Becker, Ackerman, Neuberg \& Kenrick, 2010; Schaller \& Murray, 2008) and negative cognitive assessment (Ackerman, Becker, Mortensen, Sasaki, Neuberg, \& Kenrick, 2009; Schaller, 2006) for self-protection (cited in Li, Wang, Xue, Zhao, \& Zhu, 2020). So, when faced with potential disease threat people tend to develop avoidant behaviours (e.g. avoid contact with people who have pneumonia-like symptoms (Houston \& Bull, 1994) and submit to the social norms of conformity strictly (Norris \& Friedman, 2015 cited in Li et al., 2020).

This behavioural immune system also modified our interaction with people to minimize the spread of the disease, leading to a kind of instinctive social distance. Relatively, studies have shown that we become more conformist and respectful of conventions when we feel the threat of a disease (Robson, 2020). Nevertheless, people obviously responded differently to the outbreak of coronavirus and to the spontaneous safety protocols. Actually, there were people that have intense fears about becoming infected, falling ill and fear of own mortality restrict themselves from going about but stayed home. A significant number of people become fixated to face mask, hand washing, use of hand sanitizer, and avoidance of handshakes. Besides, their personal space was consciously fortified to keep off unsolicited invasion by strangers and even familiar persons. Incidentally, fear and anxiety of coronavirus activates perceived stigmatization, xenophobia, and increasing paranoia about familiar behaviour like someone sneezing and coughing noticeably in the public. Anxiety and fears abruptly became exceedingly high; even health workers became apathetic to inpatients and outpatients as they often reject emergency cases of almost all kinds of illness brought at hospital GOPDs (observed in Federal Medical Centre,Makurdi). As a result many families and friends lost their loved ones to death. Citizens who were returning back into Nigeria from the epicenters of coronavirus such as USA, UK, Asia and elsewhere in the world decisively go into quarantine or self-isolation until they are out of the incubation period of 2 to 14 days. Some that came from the epicenters of the virus in foreign countries and states in Nigeria, for fear of stigmatization sneaked into their homes - but if reported by a whistleblower were traced and taken to establish isolation centres.

Away from the arousal of instinctive behavioural immune system response to prevent infection from the threat of this contagious viral disease, there are other people who react in the opposite way. For this group of people 
according to the reactance theory, believe they possess certain freedoms to engage in so-called free behaviour. Yet, there are times they cannot, or at least feel that they cannot, do so. When they observe that their freedom to do as they desired is threatened, psychological reactance emerges (Mühberger \& Jones, 2019; Rosenberg \& Siegel, 2017; Steindl, Jonas, Sittenthaler, Traut-Mattausch, \& Greenberg, 2016). Reactance is an unpleasant motivational arousal that emerges when people experience a threat to or lose their freedom to behave as they want. It serves as a motivator to restore one's freedom (Steindl, Jonas, Sittenthaler, Traut-Mattausch, \& Greenberg, 2016, Rosenberg, \& Siegel, 2017). Compatible with the assertion of this theory, social distance is next to impossible when people feels that their social freedom is being violated. Compatible to this fact, Mansdorf (2020) states that compliance with directives and instructed regimen is an old known problem in medical intervention. People routinely do not do what is good for them and refuse to cease behaviours that are bad for them either.

This same pattern of people behaviour and attitude should be expected when it comes to compliance with implementation of coronavirus social distance rule. Similarly, Mansdorf (2020) states that, just as people continue to smoke and drink alcohol excessively and endlessly, refuse to exercise, reject required medication, so will people test the boundaries of government instructions and many will simply refuse to conform to safety guidelines. From a psychological perspective, these people are either oppositional in their attitude or in denial regarding the effects of their refusal. While the former understands that by intentionally violating the guidelines, they are creating risk for others, and the latter deny it, at times adopting an "it won't happen to me" attitude (Mansdorf, 2020). Unmistakably, this was observed in some people opposite behaviuoral response to coronavirus and compliance to the prevention protocol recommended by NCDC and the Federal Ministry of Health in Nigeria.

\section{PEOPLE RESPONSE SOCIAL DISTANCE}

Indeed, social distance is invariably recognized to reduce disease spread, but its potential decapitated effect on the social and economic life of the society cannot be overemphasized. Apparently, a good number of Nigerians accept and complied to the social distance protocol, likewise a good population of the masses refused to comply with the social distance norm. For example, prolong period of social distancing results in loss of a productive role in a society such as frustrating social belongingness, isolation and feelings of burdensomeness. To mitigate these effects, many were clandestinely organizing and attending social events like birthday parties, weddings, burials in crowded spaces. In the religious circle, Pastors and Imams audaciously defied social distance and threw open worshipping centres for Sunday and Friday worship and 95\% of the congregation violated social distance and attended services without even wearing face mask. In some states, markets were closed but sellers and buyers were mixing and moving freely in crowds buying and selling at the peripheral of the market places without concern about getting infected and transmitting same to others. Many people ignored the reality of coronavirus existence not to talk of getting infected based on pseudo-beliefs and theories that it is a white and rich people's disease.

Others linked it to the biblical revelation of the 666 Lucifer end time warning sign and the politics of $5 \mathrm{G}$ network between China and USA. There were those that subjectively believe and claim that they will not be infected as coronavirus cannot survive the extreme hot weather of our environment. Some, both the old and the young denied but at same time went out regularly to drink high volume alcoholic beverages believing that it can immunize their 
body against getting infected. Apparently, government officials and politicians were on their own part not showing practical encouraging behavior to motivate the peoples' compliance to social distance and other prevention guidelines. They conspicuously violated social distance rule by organizing and attending political rallies for pending elections and burial ceremonies of popular politicians or their family members in large crowd. Unfortunately, the elections and attend burial ceremonies of popular deceased politicians or their family members in large crowd. Unfortunately, government disregard to the attitude of the politicians' and deliberate violation of social distance rather reinforced the oppositional group attitude and refusal to conform.

Clinically, coronavirus is a risk to life and the global records of infected persons so far was $138,118,578$ recovered 111,128,227 and death 2,974,850 (Worldometer, 2021) at the time of publishing this paper. Although despite its fatality risk potential, infected persons are surviving it. In Nigeria, as at the time of publishing this paper the current statistics shows that 163,911 persons have contracted the virus 154,225 recovered and 2,061 death were recorded (NCDC, 2020, NTA news, 2020, Worldometer, 2021). Statistically, the current report on rate of covid-19 infection suggests that the number of infection is rather on the rise with the resurgence of a second wave of the virus. As it is, it can be objectively inferred that covid-19 and its community transmission is looming in the country more than at the onset of the pandemic. This is obvious because even from the onset and peak of transmission, testing facilities and capacity was grossly inadequate in a country with a population of about 200million people. Moreover, contact tracing and some states government denial of coronavirus in their state remains a great challenge to determine the true picture of coronavirus infection rate in Nigeria.

Notwithstanding, the Presidential Task Force on covid-19 quarterly report submitted to the president Muhammed Buhari convinced him and state governors to relax the lockdown order as well as lift ban on restriction of movement. Likewise, schools, worship centres, and markets were directed to be reopened. Social, economic and commercial activities are fully restored even though the wearing of face mask, hand washing and use of hand sanitizers was emphasized and encouraged for prevention infection and community transmission. Notwithstanding, compliance to social distance generally became weakened by the lifting of ban on movement and directive on reopening of worshipping centres and commercial activities. Worst of all, flouting of social distance protocol was witnessed in the governorship election campaign in Edo and Ondo states, burial ceremonies, religious services and the recent \#ENDSARS protest. In fact, the divided response and attitude of people to coronavirus and social distance from their perception would be a mirror to help government appraisal of the people possible response to emergence control of a disease. And this will importantly help to strengthen measures on health policy on disease management and control in future outbreaks. Extrapolating from the above observation and account of the situation of covid-19 in Nigeria, this study seeks to investigate the people perception of coronavirus as existential threat and their conformance to social distance protocol.

\section{AIM AND OBJECTIVES}

The study aimed to investigate and determine the peoples' perception of a contagion disease effect as an existential threat to life and how they respond to the outbreak of coronavirus and conformance to social distance rule. The study 
was anchored on two fundamental theories which are behavioural immune system and reactance theory. The objectives are as follows:

1. To determine the perception of those who felt more threatened by the coronavirus and had to conform and adhere to the social distance safety protocol.

2. To determine the correlation in the perception of coronavirus as an existential threat between conformists and oppositional group and compliance to social distance protocol.

3. To determine the difference in the perception of coronavirus as an existential threat between conformists and oppositional group.

4. To determine the difference in male and female perception of coronavirus as an existential threat and response and response to conformance to social distance protocol.

\section{HYPOTHESES}

1. There will be a significant correlation between conformists' perception of coronavirus as an existential threat and compliance to social distance protocol.

2. There will be a significant correlation between oppositional perception of coronavirus as an existential threat and compliance to social distance protocol.

3. There will be a significant difference in the perception of coronavirus as an existential threat between conformists and oppositional group and conformance to social distance protocol.

4. There will be a significant difference between male and female perception of coronavirus as an existential threat and conformance to social distance protocol.

\section{METHODOLOGY}

\section{RESEARCH DESIGN}

Correlation research design was used as the structural plan to achieve the aim and objectives of the study by obtaining and analyzing detailed information from the participant's experience and thought of coronavirus as a contagious disease. The research design took into consideration that correlation is a statistical measure of relationship between two or more variables and indicates how one variable predict another. The design does not require manipulation of the variables and it is not expected to determine a cause-effect relationship between perception of coronavirus as an existential threat and compliance social distance protocol. Rather it is to enable predictability of probable individual response, attitude and behaviour towards future outbreak of diseases and response to prevention guidelines.

\section{POPULATION/SAMPLE}

The population for the study comprised of Nigerian citizens especially those who were living and attending outpatient clinic at NHIS and GOPD in Federal Medical Centre Makurdi, Benue state during the outbreak of the coronavirus. The selection of sample from the population was limited to Makurdi, a metropolitan capital city of Benue state. The sample size for the study was 343 persons who agreed to participate in the study willingly and with their consent to provide information on request from the researchers. NHIS and GOPD clinic were considered appropriate setting for 
data collection because it was easier to meet by happenstance people with expected demographic characteristics required for the study. Therefore, a convenient sampling technique - a nonprobability sampling method was opted for as the sampling technique for selection of participants' involvement in the study. The demographic characteristics of the participants include; sex (male and females), age range was from 18-60years old adults, religion, ethnicity, educational status, and marital status.

\section{INCLUSION CRITERIA}

1. Adults both male and female

2. Those who accepted to participate in the study.

3. Those who can read and understand English.

\section{EXCLUSION CRITERIA}

1. Those were not physically stable and in distress

2. Those that had hearing or sight defect

3. Those who refuse participation

4. Those who cannot understand and read in anything in English

\section{INSTRUMENT}

The data collection tool was a self-structured questionnaire which consists of 14 items relating to people perception coronavirus and response to social distance protocol. The questionnaire was developed with a thorough review of the literature on the novel virus disease and social distance concept and professional opinions and inputs from the authors of the study. Reliability of the tool was statistically determined using the Cronbach alpha value for internal consistency and the reliability coefficient was .76. The tool consists of participants' demographic variables of sex, age, marital status, religion, ethnicity educational status. The data collection was for 12 weeks as it was commenced in April, 2020 and completed in mid-July same`year.

\section{DATA ANALYSIS}

The Pearson correlation and t-test of independent were used for the analysis of the data collected from the participants. Pearson correlation was used to determine the relationship between the two variables on hypothesis one and two. The t-test statistics was used to determine the significant difference between conformists and oppositional group and the male and female perception of coronavirus as an existential threat and conformance to social distance for hypothesis three and four respectively. Data analysis was done using the statistical packages for social sciences SPSS version 21.0 for windows. The results are observed at the significant level of $(\mathrm{P}>0.01$ and 05$)$ level. 


\section{RESULTS}

The purpose of the study was to investigate the relationship between perception of coronavirus as an existential threat and conformance to social distance protocol. The study was anchored on the conformists who associated with behavioural immune system theory and oppositional group who are allied with the reactance theory. From the output of data analysis, the results are presented in this section.

Table 1: Pearson correlation of conformist perception of coronavirus and compliance to social distance

\begin{tabular}{|c|c|c|c|}
\hline & & Perception & Conformist group \\
\hline \multirow[t]{2}{*}{$\begin{array}{l}\text { Perception of } \\
\text { Coronavirus }\end{array}$} & $\begin{array}{l}\text { Pearson correlation } \\
\text { Sig (2-tailed) }\end{array}$ & $\begin{array}{c}1 \\
.000\end{array}$ & $.559 \square$ \\
\hline & $\mathrm{N}$ & 343 & 343 \\
\hline \multirow[t]{2}{*}{$\begin{array}{l}\text { Conformist__ } \\
\text { group }\end{array}$} & $\begin{array}{l}\text { Pearson correlation } \\
\text { Sig (2-tailed) }\end{array}$ & $\begin{array}{l}.559 \square \\
.000\end{array}$ & 1 \\
\hline & $\mathrm{N}$ & 343 & 343 \\
\hline
\end{tabular}

**. Correlation is significant at the 0.01 level (2-tailed).

The results on table 2 shows there is a significant positive correlation between perception of coronavirus as an existential threat and conformance to social distance among the conformists group, $(\mathrm{r}=.559, \mathrm{p}<.0 .01)$.

Table 2: Pearson correlation of oppositional perception of coronavirus and conformance to social distance

\begin{tabular}{llcr}
\hline & & Perception & Conformist group \\
\hline $\begin{array}{l}\text { Perception of } \\
\text { Coronavirus }\end{array}$ & $\begin{array}{l}\text { Pearson correlation } \\
\text { Sig (2-tailed) }\end{array}$ & 1 & $-.175^{\square}$ \\
& $\mathrm{N}$ & 343 & .001 \\
& Pearson correlation & & 343 \\
Oppositional group & Sig (2-tailed) & $.175^{\square}$ & 1 \\
& $\mathrm{~N}$ & .001 & 343 \\
\hline
\end{tabular}

**. Correlation is significant at the 0.01 level (2-tailed).

The results on table 2 shows there is a negative correlation between perceptions of coronavirus as an existential threat and conformance to social distance among the oppositional group, $(\mathrm{r}=-.175, \mathrm{p}<.0 .01)$. 
Table 3: T-test result for perception of coronavirus by group

\begin{tabular}{lllllllll}
\hline $\begin{array}{l}\text { Social distance } \\
\text { Protocol groups }\end{array}$ & $\mathbf{N}$ & Mean & SD & Sig & t & df & p<.05 \\
\hline Perception & & & & & & & & \\
Conformists & 178 & 12.7360 & 2.39721 & .956 & -7.012 & 341 & accepted \\
Opposition & 165 & 16.0242 & 3.03586 & & & & \\
\hline $\mathrm{P}<.05$ & & & & & & & &
\end{tabular}

Table 3 statistically revealed that there is a significant difference in the perception of coronavirus as an existential threat and conformance to social distance protocol with conformists group score of ( $\mathrm{M}=12.7360, \mathrm{SD}=2.39721$, $\mathrm{N}=178)$ and oppositional group score of $(\mathrm{M}=16.0242, \mathrm{SD}=3.03586, \mathrm{~N}=165),(\mathrm{t}(341)=-7.012, \mathrm{p}<.05)$.

Table 4: T-test result for perception of coronavirus by sex

\begin{tabular}{|c|c|c|c|c|c|c|c|c|}
\hline Sex & $\mathbf{N}$ & Mean & SD & Sig & $\mathbf{t}$ & df & \multicolumn{2}{|c|}{$\mathrm{p}<.05$} \\
\hline \multicolumn{9}{|c|}{ Perception } \\
\hline Male & 179 & 14.3520 & 4.47642 & & .956 & -7.012 & 323 & accepted \\
\hline Female & 146 & 14.5137 & 4.84979 & & & & & \\
\hline
\end{tabular}

$\mathrm{P}<.05$

Table 4 statistically revealed that there is a significant difference in the perception of coronavirus as an existential threat and conformance to social distance protocol with male group scores of $(\mathrm{M}=14.3520, \mathrm{SD}=4.47642, \mathrm{~N}=179)$ and female scores of $(\mathrm{M}=14.5137, \mathrm{SD}=4.84979, \mathrm{~N}=146),(\mathrm{t}(323)=-3.312, \mathrm{p}<.05)$.

\section{DISCUSSION}

The study was carried out in Makurdi the capital of Benue state in Nigeria. From the statistical analysis obtained, the discussion of the findings was provided in the sequence of the stated hypotheses.

Deducing from the statistics derived, table 1 results which represent the first hypothesis which state that there will be a significant correlation between conformists' perception of coronavirus as an existential threat and compliance to social distance protocol was accepted. This indicate that there is a significant positive correlation between conformists' perception of coronavirus as an existential threat and compliance with social distance protocol, $(\mathrm{r}=.559$, $\mathrm{p}<.0 .01)$. This result agrees with Robson, 2020 who asserted from the behavioural immune system perspective, that people are conscious of their own health and in an event of perceived contagious disease situation, they automatically trigger a deeply evolved responses to disease due to fears of contagion which led us to become more conformists... and less accepting of eccentricity. According to behavioural immune system theory (John, Natalie, \& Michael, 2013) people are likely to stir responses for self-protection (cited in Li, Wang, Xue, Zhao, \& Zhu, 2020). So, when faced with potential disease threat people tend to develop avoidant behaviours (e.g., avoid contact with people who have pneumonia-like symptoms (Houston \& Bull, 1994) and submit to the social norms of conformity strictly (Norris \& 
Friedman, 2015 cited in Li et al., 2020). Behavioural immune system also modified our interaction with people to minimize the spread of the disease, leading to a kind of instinctive social distance. Consequently, anything that is seen to reduce the risk of infection in the first place is quickly adopted to have a distinct advantage. This has importantly justified the reason why some people (conformists) in Nigeria became fixated to wearing face mask, washing hand, use of hand sanitizer, and maintained social distance by fortifying their personal space for unsolicited invasion by strangers and even familiar persons.

On hypothesis two which states that there will be a significant correlation between oppositional perception of coronavirus as an existential threat and compliance to social distance protocol represented on table 2 was also accepted. However, in a different direction which indicates a negative correlation between perceptions of coronavirus as an existential threat and conformance to social distance among the oppositional group, $(r=-.175, p<.0 .01)$. This doubtlessly implies that the oppositional group as people allied with the reactance theory actually may regard coronavirus as an existential threat and the need to conformance to social distance. Nevertheless, by statistical principle, a negative correlation is the opposite movement of two variables where an increase in one variable predictably meets with a comparable decrease of the other. Therefore, the attitude of oppositional group unequivocally depicts an opposite picture of ascending-descending response towards coronavirus by recognizing its contagiousness and fatal effect. Yet, they absolute did not want to comply with the social distance protocol as it was practically observed among some people in Nigeria. This was observed from the findings derived on the statistical analysis of hypothesis three discussed in adjoining paragraph.

Table 3 which represent the third hypothesis revealed that there is a significant difference in the perception of coronavirus as an existential threat and conformance to social distance protocol with conformists group score of $(\mathrm{M}=12.7360, \mathrm{SD}=2.39721, \mathrm{~N}=178)$ and oppositional group score of $(\mathrm{M}=16.0242, \mathrm{SD}=3.03586, \mathrm{~N}=165),(t(341)=$ $7.012, \mathrm{p}<.05)$. Certainly, the oppositional group perception of coronavirus as an existential threat and conformance to social distance protocol showed a negative correlation. However, hypothesis three $t$-test results have absolutely explained the principle behind the negative correlation which reflected oppositional perception of coronavirus and conformance to social distance. The expression of a significant difference as shown from the $t$-test results is an affirmation of the reactance theory regarding people with oppositional attitude. The theorists postulate that there are people who believe that they possess certain freedoms to engage in so-called free behaviour. But, when they perceive that their freedom and desire to do so is threatened, psychological reactance emerges (Mühberger \& Jones, 2019; Rosenberg \& Siegel, 2017; Steindl, Jonas, Sittenthaler, Traut-Mattausch, \& Greenberg, 2016) to become oppositional. Reactance is an unpleasant motivational arousal that emerges when people experience a threat to or loss of their free behvaiour. It serves as a motivator to restore one's freedom (Steindl, Jonas, Sittenthaler, Traut-Mattausch, \& Greenberg, 2016, Rosenberg, \& Siegel, 2017).

Thus, regardless of the fact that there were people conforming to social distance protocols as they perceived coronavirus as an existential threat, a large proportion of the Nigerian population also declined conformance to the social distance norm recommended by the NCDC. Of course, people routinely do not do what is good for them and refuse to cease behaviours that are bad for them either (Mandorf, 2020). Indeed, compliance to social distance deliberately was not observed among many Nigerians. Many people were clandestinely organizing and engaging in 
crowded socioeconomic and political activities like the governorship election campaign in Edo and Ondo states, crowded burial ceremonies, and \#ENDSARS protest. From a psychological perspective, according to Mansdorf, (2020) these are people who are either oppositional in their attitude or in denial regarding the effects of coronavirus on their health by their intentional violation of the safety guidelines at times adopting an "it won't happen to me" attitude.

The results on table 4 represent the fourth hypothesis which states that there will be a significant difference between male and female perception of coronavirus as an existential threat and conformance to social distance protocol was not accepted. However, a slight significant difference was observed in the males and females mean scores regarding the perception of coronavirus as an existential threat and conformance to social distance protocol between. The male shows a score of $(\mathrm{M}=14.3520, \mathrm{SD}=4.47642, \mathrm{~N}=179)$ and female score of $(\mathrm{M}=14.5137, \mathrm{SD}=4.84979$, $\mathrm{N}=146),(\mathrm{t}(323)=-3.312, \mathrm{p}<.05)$. Apparently, these findings corresponded with the environmental observation of the men and women behavioural response to coronavirus in Nigeria. Most men were obviously concerned and they express fear of contracting the virus, but the women were more apprehensive and fearful about getting infected and ending up in isolation centres or even dying and living behind children which no one would take care of like they would have done. Anxiety and fears abruptly became exceedingly high in the public space. Even in hospitals, medical health workers became fearful and exhibits apathetic attitudes toward patients with cough and other pneumonia-like symptoms. By and largely, the women exhibited more compliance to social distance by restricting their outdoor activities in the public space than the men.

\section{IMPLICATION FOR THE STUDY}

The outbreak of coronavirus also called Covid- 9 as a pandemic disease is a major $21^{\text {st }}$ century global health challenge. It has afflicted an unprecedented burden on the physical and mental health of the global population. The global mortality rate experience from the tumultuous wave of the scourge of the coronavirus disease was really catastrophic. In fact, the unpredictable outbreak of coronavirus pandemic brought a great on public health system across the world. Unfortunately, Nigeria like other countries in Africa has never had a robust healthcare system that can absorb the sudden wave of coronavirus infection of its population of about 200million people. As a result, it was pertinent that the government and the people must remain conscious of our presently situation and take precautions to prevent infection and transmission of it. Nigerians should be prepared to welcome and accept the vaccine produced made available to inoculate the human immunity against contraction of this virus. Furthermore, it is important and necessary for everyone to know that the non-pharmacotherapy practice is the best behavioural response and most effective option for the control of the transmission and survival from coronavirus. Besides, the diametrical attitudes and response of the people towards coronavirus and social distancing should help to deepen government understanding of the human behavioral response to outbreak of disease. This should give government and health managers the opportunity to learn and strengthened comprehensive measures on health policy on disease control in future outbreaks. 


\section{CONCLUSION}

Coronavirus pandemic is a disease that is currently on rampage and it minds no individual race, sex, socioeconomic and political status, ethnicity, religious background and nationality. It infects all and sundry irrespective of your age. Surmising from the outcome of the study, coronavirus is generally perceived as an existential threat to life. But there is clear evidence of a dichotomy in peoples' attitude and response toward. Other people oblige and stuck to observe the prevention and transmission protocols such as social distance but many others disobeyed and violate it. The former are the conformists who according to behavioural immunue system inevitably trigger up the deeply evolved response to disease due to fears of contagion. So, by recognizing the potential threat of coronavirus they tend to develop avoidant behaviours and submit to the social norms of conformity strictly. Behavioural immune system inclination helps to modify people interaction to minimize the spread of disease, leading to a kind of instinctive social distance. The latter, are those on the other side of the divide, and are known as the oppositional group. They according to the reactance theory attached more significance to their free behaviuor develop a negative and resistance attitude to social distance. They snubbed the rules of compliance to coronavirus safety health guidelines as a protest against perceived threat to their freedom to do as they desire. Interestingly, this diametrical opposing behaviour of the participants in this study reveals one good reason it is difficult to tackle a disease outbreak like coronavirus head-on and end it swiftly.

\section{FUNDING}

This study was strictly funded from out-of-pocket finances.

\section{CONFLICT OF INTEREST}

The authors have no misunderstanding in the entire process and stages of writing and financing of the paper for publication.

\section{ACKNOWLEDGEMENT}

We appreciate Dr. Peteru Inunduh, Medical Director Federal Medical Centre Makurdi for been magnanimous to support to authors with finances to complete the study. We also thank Francis Udzuah for his diligent statistical analysis of the data collected. 


\section{REFERENCES}

Centre for Disease Control and prevention (2020). Social distance, quarantine and isolation. Retrieved from www.cdc.com

Federal Ministry of Health (2020). First case of coronavirus confirmed in Nigeria. Retrieved from https://www.health .gov.ng

Honeycut, J.M. (2020). Personality can predict who's a rule follower and who flouts Covid-19 social distancing guidelines. The Conversation. Retrieved from https://the conversation.com

Li, S., Wang, Y., Xue, J., Zhao, and Zhu, T. (2020). The impact of Covid-19 epidemic declaration on psychological consequences: a study on active Weibo users. International Journal of Environmental Research and Public health. 17, 2032, doi: 10.3390/ijerph17062032

Mansdorf, J.I. (2020). Enforcing compliance with Covid-19 pandemic restrictions: Psychological aspects of a national security threat. Retrieved from https://preventiveweb.net/go/70917.

Mühlberger, C., and Jones, E. (2019). Reactance theory. Social Psychology in Action, pp 79-94. Retrieved form link.springer.com

Nigerian Center for Disease and Control (2020). Guidelines on social distancing. Retrieved from covid19.ncdcgov.org>files

Petterson, H., Manley, B., and Hamandez, S. (2020). Tracking coronavirus global spread. Retrieved from www.cnn.com>interactive health.

Robson, D. (2020). The fear of coronavirus is changing our psychology. Retrieved from www.bbc.com

Rosenberg, B.D., and Siegel, J.T. (2020). A 50-year review of psychological reactance theory: American Psychological Association. Retrieved from https://dxdio.org/10.1037/mot0000091.

Sanderson, D. (2020). Coronavirus an "existential threat' to African and her crowed slums. Retrieved from https://the conversation.com/coronavirus-an-existential-threat-to-africa-and-her-slums.

Steindl, C., Jonas, E., Sittenthaler, S., Traut-Mattausch, E., and Greenberg, J. (2016). Understanding psychology of reactance. New dimension and findings. Psychology. Retrieved from DIO: 10.1027/2151-2604/a000222.

Worldometer $\left(14^{\text {th }}\right.$ April, 2021). Coronavirus pandemic update. Retrieved from https://www.worldometer.info. 